\title{
PER QUĖ JOAN DUNS ESCOT, AL CAPVESPRE?
}

Josep-Ignasi Saranyana

Universidad de Navarra

saranyana@unav.es

Se’m demana que m'expliqui sobre la meva actual dedicació investigadora, després d'aconseguir la condició de Professor emèrit, i com és que ara he arribat, al capvespre de la meva activitat científica, a estar tan interessat en la síntesi de Joan Duns Escot, i no pas abans.

La meva investigació medievalística va començar, a les acaballes dels seixanta, de la mà de Sant Bonaventura, amb una tesi doctoral sobre la teologia de la història bonaventuriana, defensada a l'any 1972 . Vaig haver de resseguir els vuit feixucs volums de les seves obres completes, en la magnifica edició dels framenors de Quaracchi. Tanmateix, ben aviat em vaig adonar que em calia capbussar-me en la teologia i la filosofia de Tomàs d'Aquino, si volia aclarir-me en el gran debat intel-lectual del segle XIII, provocat, com tothom sap, per la recepció a París del genuí Aristòtil metafísic (on arribà primer de la mà d'Avicenna, després presentat per Averrois, i finalment traduït directament del grec).

En aquells anys inicials de la meva tasca investigadora, res de res de Duns Escot, llevat d'un treball primerenc que vaig publicar a l'any 1982, amb motiu del vuitè centenari del naixement de Sant Francesc d'Assís (Saranyana 1982). Tant és així que quan vaig editar per primera vegada el meu manual Historia de la filosofía medieval, a l'any 1985 , em vaig limitar, en l'epígraf dedicat a Duns, a embastar unes quantes idees extretes de les magnífiques exposicions d'Étienne Gilson i d'Efrem Bettoni i poc més. No recordo si vaig fer alguna lectura directa de les obres de Duns, encara que em sembla inversemblant que ho fes, perquè me'n recordaria, donada l'extrema dificultat conceptual del sintètic llatí de l'Escot.

De mica en mica, però, Bonaventura va quedar arraconat en la meva feina i Aquino prengué cada cop més protagonisme. De fet, la meva tesi filosòfica, alguns anys posterior, va ser sobre un argument en el qual Tomàs tingué un gran protagonisme (la discussió medieval sobre la condició femenina).

La vida acadèmica continuava i heus aquí que un bon dia, seria cap al 2000, esgotades les tres primeres edicions del meu manual Historia de la filosofia medieval, el Dr. Juan Cruz Cruz em va demanar que n'escrigués una versió nova, ben revisada i actualitzada, que finalment va veure la llum a la primavera del 2003. Va 
ser durant aquesta revisió que em vaig adonar que mai de la vida no havia entès ben bé el que havia volgut dir-nos Duns. Això em va aclaparar força i m’atabalà una mica. Redactava el capítol dedicat a Escot i..., som-hi, a descabdellar la troca i tornar a començar! Així un dia i un altre durant una bona temporada. El llatí de Duns, de facil sintaxi i vocabulari limitat, em resultava, tanmateix, incomprensible des del punt de vista conceptual. De vegades em pensava que no me'n sortiria. Me n'adonava que havia entrat en un altre món, desconegut per mi, amb interessos ben diferents. Encara no havia descobert fins a quin punt les fonts d'inspiració escotista eren el seu mestre Bonaventura (si bé portat fins al seu límit) i la metafísica avicenniana.

A tot això recordo un vespre a Colònia, precisament el dia de l'ensorrament de les torres bessones de Nova York, és a dir, l'iı de setembre de 200I. Sopava amb el Prof. Albert Zimmermann. Tots dos érem ben sols a un restaurant, ignorants completament del que havia succeït a Amèrica (sic), quan vet aquí que ell em va fer un parell de comentaris sobre Duns, que em van obrir un panorama nou.Tot parlant sobre la noció de l'infinit a Duns, em va comentar incidentalment que Escot havia pretès re-fundar la metafísica. Aquest comentari dit de passada va capgirar la meva percepció de la síntesi escotista. De cop i volta les coses se'm van aclarir. Tan bon punt vaig tornar a Pamplona, vaig cercar un treball de Ludger Honnefelder, intitulat precisament Der zweite Anfang der Metaphysik, i de mica en mica vaig començar a copsar què havia pretès Duns, tot esbrinant les reflexions escotistes en el formidable i llarguíssim pròleg del seu Opus oxoniense.

Escot no havia pretès bastir una metafísica alternativa a la d'Aquino, com jo sempre havia defensat, situant-lo en el context de les diatribes de I270 i I 277 sobre l'aristotelisme heterodox; més aviat havia cercat de resoldre els problemes destapats per la metafísica aquiniana, tot i que analitzats des de la tradició filosòfica avicenniana i bonaventuriana. D'aquesta manera vaig poder sortir del bardissar en que em trobava, per entrar en un altre que m'ha portat fins avui, perquè em calia de-construir la meva comprensió d'Escot i enllestir-ne una altra completament nova. Amb prou feines vaig redactar uns quants fulls per a la nova edició de la meva Historia, que vaig lliurar a la impremta, a l'abril de 2003. Ningú no em va dir res: cap crítica es va fer ressò dels meus dubtes i del poc encert de les meves conclusions.

Així, doncs, des de la versió del meu manual, molt ampliada i amb un nou títol, de l'any 2003, fins a la seva tercera edició, eixida l'any 20II (Saranyana 20II), el Doctor Subtil ha estat sempre el meu trencaclosques. En cada una d'aquestes tres edicions he desteixit el capítol a ell dedicat per a refer-lo completament, i mentrestant, entre 2004 i 2008, he publicat quatre treballs sobre aquest autor franciscà, que m'han ajudat a familiaritzar-me una mica amb la seva síntesi filo- 
sòfica. L'últim d'aquests ha estat un estudi sobre la tesi d'habilitació de Martin Heidegger; una tesi de gramàtica especulativa, dedicada a un opuscle de Thomas Erfurt, deixeble de Duns, que el jove Heidegger pensava que era obra autèntica d'Escot (Saranyana 2008).

Al cap i a la fi,i al capvespre de la meva activitat científica, penso que Duns és, d'una banda, la balda més important entre l'antiguitat i la modernitat (sense excloure-hi ni Kant ni Heidegger), i que, alhora, és el millor contrast per entendre la revolució aquiniana, consistent en el descobriment de la trascendentalitat de l'esse.

Post scriptum.Ve a tomb, per exemplificar que mai no es pot donar per acabada la comprensió del beat Joan Duns, una experiència que he tingut mentre redactava aquesta comunicació. Per un casual, estava també embrancat en la redacció d'un capítol dedicat a Escot que anirà en un manual d'història de la teologia que estic preparant. I m'ha tornat a succeir el mateix que abans, quan vaig començar a interessar-me per la metafísica del framenor: m'he topat ara amb una dificultat extrema per copsar la seva trinitologia, fins que — després d'encomanar-me a tots els sants - me n'he adonat que també aquí, quan s'estudia la seva teologia, cal oblidar-se d'Aquino si realment es vol albirar els viaranys per on camina la teologia escotista; cal mirar més enrere i, en aquest cas, no tant voltar-se cap a Avicenna, ans molt més enllà, fins Sant Agustí, sense perdre el record de la síntesi bonaventuriana. El punt de partença escotista són les tres persones divines, la "producció" de les quals cal explicar. La generació del Verb entesa com la intel-lecció de la memòria fecunda ("dictio memoriæ fæcundæ") s'assembla ben poc a l'explicació oferta per Aquino quan es pregunta, al seu torn: "utrum aliqua processio in divinis generatio dici possit". Sant Tomás comença per les dues processions immanents revelades i passa seguidament a l'estudi de les persones divines. Escot ho fa a l'inrevés.

Al capdavall, i com en diem a casa nostra: qui no vulgui pols, que no vagi a la guerra...

\section{REFERÈNCIES}

Saranyana, J. I., "El pensamiento teológico franciscano: San Buenaventura, Duns Escoto, Guillermo de Ockham”, Scripta Theologica, I4 (1982), pp. 847-86I.

Saranyana, J. I., "Onto-teología en Juan Duns Escoto", a T. Trigo (ed.), Dar razón de la esperanza. Homenaje al Prof. Dr. José Luis Illanes, Pamplona, 2004, pp. I26I-I275. 
Saranyana, J. I., "Primo in intellectu cadit ens. Juan Duns Escoto frente a Tomás de Aquino”, a M. Carbajo Núñez (ed.), Giovanni Duns Scoto. Studi e ricerche nel VII Centenario della sua morte, Roma, 2008, pp. 26I-272.

Saranyana, J. I., "Duns Escoto leído por Heidegger", a C. A. Lertora MenDOZA (coord.), Actas del XII Congreso de filosofía medieval Juan Duns Scoto, Buenos Aires, 2008 (CD-ROM).

Saranyana, J. I., "Zur Theologie als praktischer Wissenschaftim I4. Jahrhundert", a M. Lutz-Bachmann i A. Fidora (eds.), Handlung und Wissenschaft. Die Epistemologie der praktischen Wissenschaften im I3. und I4. Jahrhundert, Berlin, 2008, pp. I43-I5I.

Saranyana, J. I., La filosofia medieval. Desde sus origenes patrísticos hasta la Escolástica barroca $\left[2003^{\mathrm{r}}\right]$, Pamplona, $201 \mathrm{I}^{3}$. 